\title{
PENGARUH STRATEGI BERHITUNG (DIFFERENT STRATEGIES) TERHADAP HASIL BELAJAR MATEMATIKA SISWA PADA OPERASI BILANGAN BULAT DI KELAS III SD NEGERI NO 114349 SIDUA-DUA
}

\author{
Oleh: \\ Nurdalilah* \\ * Dosen Tetap Jurusan Pendidikan Matematika FKIP \\ Universitas Muslim Nusantara Al Washliyah Medan \\ *Jalan Garu II No 2, Medan \\ Email: * nurdalilah1989@gamil.com
}

\begin{abstract}
:
This study aims to find out (1) students 'learning outcomes of mathematics taught with different strategies, (2) students' mathematics learning outcomes taught by traditional algorithms, (3) Are there different effects of counting strategies on results learn mathematics students on integer operation material. This research is a quantitative research with kind of quasi-experimental research. The population in this study were all third grade students of Public Elementary School 114349. The sample in this study was class III- 1 as an experimental class with a total of 30 students and class III- 2 as a control class with a total of 30 students. The findings in this study indicate that classes taught by using different strategies have an average value of 31.970 and the classes taught by algorithm have an average value of 28,5758. The results of hypothesis testing show that $t$ count> t table is 2.925> 2.0018 with the conclusion that students' mathematics learning outcomes are taught with different strategies better than those taught with traditional algorithms on integer operation material in Public Elementary School No. 114349 Academic Year 2016/2017
\end{abstract}

Keyword:

Numeracy strategies, Mathematics learning outcomes

\section{A. Pendahuluan}

Matematika adalah salah satu bidang pengetahuan yang dijadikan pengetahuan dasar, karena dengan belajar matematika mampu mengembangkan nalar. Tetapi pada kenyataannya kecintaan siswa terhadap matematika masih relatif rendah. Data yang diperoleh menyatakan "Data UNESCO berdasarkan penelitian Trends in International Mathematics and Science Study (TIMSS) pada tahun 1999 menempatkan Indonesia berada di peringkat ke 34 dari 38 negara pada mata pelajaran matematika, masih di bawah Malaysia dan Singapura".

Siswa menyenangi matematika hanya pada tahap permulaan, yaitu saat berkenalan dengan matematika sederhana. Makin tinggi tingkatan sekolahnya, matematika yang dipelajari makin sukar dan semakin banyak pula kesulitannya. 
Banyak alasan yang dilontarkan, matematika pelajaran yang sulit dipahami, sukar, dan memusingkan. Persepsi siswa terhadap matematika juga sangat buruk, dimana kebanyakan siswa beranggapan bahwa matematika hanya berguna untuk berhitung, sedangkan materi lain tidak atau kurang bermanfaat dalam kehidupan sehari-hari siswa denganide-ide matematika dalam pembelajaran di kelas penting dilakukan agar pembelajaran bermakna. Bila siswa belajar matematika terpisah dari pengalaman mereka sehari-hari maka siswa akan cepat lupa dan tidak dapat mengaplikasikan matematika.

Hal tersebut tergambar ketika seorang guru memberikan pertanyaan kepada siswa mengenai materi yang telah dijelaskan, siswa cenderung diam dan tidak mampu menjawab pertanyaan tersebut. Siswa mengalami kesulitan untuk mengingat pengetahuan yang telah didapatkan sebelumnya, dikarenakan siswa cenderung mengandalkan guru sebagai pusat informasinya. Akibatnya sering kali terjadi permasalahan yang menyebabkan hasil belajar matematika siswa rendah dan tidak memuaskan.

Selain hasil belajar siswa yang masih rendah, siswa juga masih banyak yang belum memiliki minat untuk mempelajari mata pelajaran matematika. Hal tersebut dikarenakan guru masih sering menggunakan metode ceramah dibandikan menggunakan metode dan model pembelajaran lainnya. Metode ceramah menurut Huda, (2006) mengemukakan bahwa metode ceramah dapat diartikan sebagai cara menyajikan pelajaran melalui penuturan secara lisan atau penjelasan langsung kepada sekelompok siswa. Menurut Suyono, (2014) mengemukakan metode ceramah adalah penuturan atau penjelasan guru secara lisan, di mana dalam pelaksanaanya guru dapat menggunakan alat bantu mengajar untuk memperjelas uraian yang disampaikan kepada murid-muridnya. Dari pendapat dua ahli di atas maka dapat disimpulkan bahwa metode ceramah adalah metode pembelajaran dimana guru menyajikan, menguraikan dan menjelaskan materi ajar dengan lisan kepada seluruh peserta didik.

Untuk mengatasi hal tersebut, dalam proses pembelajaran matematika bisa menggunakan strategi berhitung. Strategi berhitung merupakan suatu keterampilan intelektual sangat bermanfaat bagi seseorang. Penguasaan keterampilan dalam berhitung juga bermanfaat untuk banyak hal, seperti membantu mengatasi segala persoalan dalam kehidupan praktis sehari-hari, membantu mempermudah pemahaman konsep-konsep yang dipelajari, dan membantu mempermudahkan penguasaan ilmu pengetahuan dan teknologi yang diminati (Al-Tabany, (2014:20).

Menyadari bahwa penguasaan keterampilan berhitung sangat penting. Namun, kenyataannya banyak siswa yang lemah (kurang) dalam keterampilan tersebut. Untuk mengingatkan kemampuan tersebut diperlukan strategi yang dapat memotivasi dan sekaligus meningkatkan kemampuan siswa agar penguasaan keterampilan berhitung siswa menjadi optimal.

Dalam penguasaan keterampilan serta strategi berhitung, pada dasarnya dituntut untuk melakukan prosedur dan operasi dalam matematika secara cepat dan benar. Keterampilan yang dimiliki siswa didasarkan atas pemahaman terhadap konsep dan teorema yang telah dipelajarinya. Dari hasil pemahaman tersebut, siswa kemudian mencoba latihan-latihan yang cukup (tidak perlu berlebihan) untuk menguatkan memori terhadap konsep dan teorema yang telah dipelajarinya. Untuk itu ada tahapan yaitu; (1) latihan mengingat, (2) konsep 
Nurdalilah: Pengaruh Strategi Berhitung (Different Strategies) terhadap Hasil Belajar Matematika Siswa pada Operasi Bilangan Bulat di Kelas III SD Negeri No 114349 Sidua-Dua

verbal, (3) konsentrasi sejumlah kecil konsep, (4) latihan singkat dan berulangulang, (5) konsep dipelajari kembali, dan (6) jadwal latihan (Shoimin, 2014:35).

Berdasarkan uraian di atas maka peneliti tertarik untuk melaksanakan penelitian dengan judul "Pengaruh Strategi Berhitung (Different Strategies) Terhadap Hasil Belajar Matematika Siswa Pada Materi Operasi Bilangan Bulat di Kelas III SD Negeri No 104261 Sidua-dua"

\section{B. Metode Penelitian}

Metode penelitian ini merupakan kuasi eksperimen atau eksperimen semu. Sampel dikelompokkan menjadi dua kelompok yaitu satu kelas eksperimen dan satu kelas kontrol. Kelas eksperimen menggunakan strategi berhitung (different strategies), sedangkan kelas kontrol menggunakan algoritma tradisional. Variabel bebas dalam penelitian ini terdiri atas dua jenis yaitu strategi berhitung (different strategies) dan algoritma tradisional sedangkan variabel terikatnyaa adalah hasil belajar matematika pada operasi bilangan bulat.

Penelitian ini dilaksanakan di SD Negeri No 114349 Sidua-dua. Penelitian ini berlangsung pada tanggal 25 April 2017 s/d 12 Mei 2017. Populasi dalam penelitian ini adalah Populasi dalam penelitian ini adalah seluruh siswa kelas III SD Negeri No 114349 Sidua-dua Tahun Ajaran 2016/2017 yang berjumlah 88 siswa.

Dalam desain ini terdapat dua kelompok yang dipilih secara random dijadikan sebagai kelas eksperimen dan kelas kontrol, seperti pada tabel 1 berikut:

Tabel 1. Desain Penelitian

\begin{tabular}{|c|c|c|c|}
\hline Kelompok & Pre - test & Perlakuan & Post - test \\
\hline Eksperimen & $\mathrm{T}_{1}$ & $\mathrm{X}_{1}$ & $\mathrm{~T}_{2}$ \\
\hline Kontrol & $\mathrm{T}_{1}$ & $\mathrm{X}_{2}$ & $\mathrm{~T}_{2}$ \\
\hline
\end{tabular}

\section{Keterangan :}

$\mathrm{X}_{1} \quad$ : Perlakuan menggunakan Strategi Berhitung (different strategies)

$\mathrm{X}_{2} \quad$ : Perlakuan menggunakan algoritma tradisional

$\mathrm{T}_{1} \quad$ : Pre-test (Tes awal)

$\mathrm{T}_{2} \quad$ : Post-test (Tes akhir)

Teknik Pengumpulan data dalam penelitian ini menggunakan instrumen tes. Tes ini digunakan untuk mengetahui hasil belajar matematika dalam memahami konsep matematika. Tes yang diberikan pada akhir pembelajaran (post-test), hasil post-test inilah yang merupakan data untuk mengetahui hasil belajar matematika siswa dalam pembelajaran matematika dengan materi operasi bilangan bulat. Tes yang digunakan adalah tes berbentuk essai yang terdiri 5 soal. Materi yang diujikan adalah materi operasi bilangan bulat

Data yang diperoleh dari hasil tes awal dan tes akhir dianalisis untuk mengetahui pengaruh strategi berhitung terhadap hasil belajar matematika. Selanjutnya menguji normalitas dan homogenitas sebagai prasyarat untuk uji statistik parametrik yang terakhir melakukan uji hipotesis. 


\section{Hasil Penelitian \\ 1. Uji Statistik Inferensial}

Dalam proses analisis tingkat lanjut untuk menguji hipotesis, perlu dilakukan uji persyaratan data meliputi: Pertama, bahwa data bersumber dari sampel yang dipilih secara acak. Kedua, sampel berasal dari populasi yang berdistribusi normal. Ketiga, kelompok data mempunyai variansi yang homogen. Pengambilan sampel secara acak telah diketahui berdasarkan teknik sampling pada pemaparan metodologi pada bab sebelumnya, sedangkan pada bab ini dilakukan persyaratan analisis normalitas dan homogenitas dari distribusi data yang diperoleh.

Tabel 2. Hasil Uji Normalitas Tes Hasil Belajar Matematika

\begin{tabular}{|c|c|c|c|c|c|c|c|c|}
\hline \multirow{2}{*}{ Kelompok } & \multicolumn{4}{|c|}{ Pre-test } & \multicolumn{4}{c|}{ Post-test } \\
\cline { 2 - 9 } & $\mathbf{L}_{\text {hitung }}$ & $\mathbf{N}$ & $\mathbf{L}_{\text {tabel }}$ & Kriteria & $\mathbf{L}_{\text {hitung }}$ & $\mathbf{n}$ & $\mathbf{L}_{\text {tabel }}$ & Kriteria \\
\hline Eksperimen & 0,158 & 30 & 0,1618 & Normal & 0,144 & 30 & 0,1618 & Normal \\
\hline Kontrol & 0,156 & 30 & 0,1618 & Normal & 0,120 & 30 & 0,1618 & Normal \\
\hline
\end{tabular}

Dari tabel terlihat bahwa $\mathrm{L}_{\text {hitung }}<\mathrm{L}_{\text {tabel}}$, yang berarti kedua data pre-test berdistribusi normal. Sedangkan $\mathrm{L}_{\mathrm{hitung}}$ untuk data post-test kelas eksperimen diperoleh adalah kedua nilai juga kurang dari $\mathrm{L}_{\text {tabel. }}$. Berarti kedua data post-test juga berdistribusi normal.

Tabel 3. Hasil Uji Homogenitas

\begin{tabular}{|c|c|c|c|c|c|c|c|c|}
\hline \multirow{2}{*}{ Kelompok } & \multicolumn{4}{|c|}{ Pre-test } & \multicolumn{4}{|c|}{ Post-test } \\
\hline & Varians & Dk & $\mathbf{F}_{\text {hitung }}$ & $\mathbf{F}_{\text {tabel }}$ & Varians & dk & $\mathbf{F}_{\text {hitung }}$ & $\mathbf{F}_{\text {tabel }}$ \\
\hline Eksperimen & 4,229 & 30 & 1,064 & 1,864 & 25,531 & 30 & 1,342 & 1,864 \\
\hline Kontrol & 3,972 & 30 & & & 18,940 & 30 & & \\
\hline
\end{tabular}

Dari tabel diperoleh bahwa untuk data pre-tes $\mathrm{F}_{\text {hitung }}<\mathrm{F}_{\text {tabel }}(1,064<$ 1,864), sehingga dikatakan sampel dalam penelitian ini homogen. Demikian juga untuk data post-test diperoleh bahwa $\mathrm{F}_{\text {hitung }}<\mathrm{F}_{\text {tabel }}(1,342<1,864)$, sehingga dikatakan sampel dalam penelitian ini homogen.

Telah diketahui bahwa kedua kelompok data hasil belajar matematika siswa adalah berdistribusi normal dan mempunyai varians yang homogen. Pengujian hipotesis terhadap hasil belajar matematika siswa dapat dilihat pada tabel berikut

Tabel 4. Hasil Uji Hipotesis

\begin{tabular}{|c|c|c|c|c|c|c|c|c|}
\hline \multirow{2}{*}{ Kelompok } & \multicolumn{4}{|c|}{ Pre-test } & \multicolumn{4}{|c|}{ Post-test } \\
\cline { 2 - 9 } & $\begin{array}{c}\text { Rata- } \\
\text { rata }\end{array}$ & $\mathbf{d k}$ & $\mathbf{t}_{\text {hitung }}$ & $\mathbf{t}_{\text {tabel }}$ & $\begin{array}{c}\text { Rata- } \\
\text { rata }\end{array}$ & $\mathbf{d k}$ & $\mathbf{t}_{\text {hitung }}$ & $\mathbf{t}_{\text {tabel }}$ \\
\hline Eksperimen & 21,667 & 58 & $-0,128$ & 2,001 & 31,970 & 58 & 2.925 & 2,001 \\
& & & 8 & 28,578 & & \\
\hline Kontrol & 21,600 & & & &
\end{tabular}


Nurdalilah: Pengaruh Strategi Berhitung (Different Strategies) terhadap Hasil Belajar Matematika Siswa pada Operasi Bilangan Bulat di Kelas III SD Negeri No 114349 Sidua-Dua

Berdasarkan tabel tersebut dengan membandingkan harga $t_{\text {hitung }}$ untuk taraf nyata $\alpha=0,05$ dengan $\mathrm{dk}=30+30-2=58$ diperoleh nilai $t_{0,05(58)}=$ 2,0018 berarti $t_{\text {hitung }}>t_{\text {tabel }}$ atau 2,925 $>2,0018$ maka Ha diterima dan Ho ditolak yang berarti bahwa "Terdapat Pengaruh Strategi Berhitung (Different Strategies) Terhadap Hasil Belajar Matematika Siswa Pada Operasi Bilangan Bulat di Kelas III SD Negeri No 114349 Sidua-dua Tahun Ajaran 2016/2017.

\section{Uji Statistik Deskriptif}

Setelah diketahui nilai pretest siswa dan telah dibentuk kelompok kemudian dilakukan pembelajaran dengan dua strategi pembelajaran yang berbeda pada kelas eksperimen dan kelas kontrol. Kelas eksperimen menggunakan strategi pembelajaran strategi berhitung (different strategies) sedangkan kelas kontrol menggunakan strategi pembelajaran aalgoritma tradisional. Pada akhir pertemuan, siswa diberikan post-test untuk mengetahui hasil belajar matematika siswa setelah diberikan perlakuan. Secara ringkas hasil post-test kedua kelas diperlihatkan pada tabel berikut:

Tabel 5. Hasil Post test

\begin{tabular}{|c|c|c|c|c|c|c|}
\hline Kelompok & N & Rata-rata & Varians & $\begin{array}{c}\text { Standar } \\
\text { Deviasi }\end{array}$ & Maksimal & Minimal \\
\hline Eksperimen & 30 & 31,970 & 25,532 & 5,053 & 47 & 19 \\
\hline Kontrol & 30 & 28,576 & 18,940 & 4,352 & 50 & 15 \\
\hline
\end{tabular}

Makna dari data di atas adalah hasil belajar matematika siswa yang diajarkan dengan menggunakan strategi berhitung (different strategies) mempunyai nilai yang beragam atau berbeda antara siswa yang satu dengan yang lainnya. Secara kuantitatif dapat dilihat pada tabel berikut ini:

Tabel 6. Distribusi Frekuensi Data Post-test Kelas Eksperimen

\begin{tabular}{|c|c|c|c|}
\hline No & Kelas Interval & $\mathbf{F}$ & F Relatif \\
\hline 1 & $19-22$ & 4 & $13,33 \%$ \\
\hline 2 & $23-26$ & 6 & $20 \%$ \\
\hline 3 & $27-30$ & 2 & $6,67 \%$ \\
\hline 4 & $31-34$ & 4 & $13,33 \%$ \\
\hline 5 & $35-38$ & 4 & $13,33 \%$ \\
\hline 6 & $39-42$ & 0 & $0 \%$ \\
\hline 7 & $43-46$ & 7 & $23,33 \%$ \\
\hline 8 & 47 & 3 & $10 \%$ \\
\hline \multicolumn{2}{|r|}{ Jumlah } & 30 & $100 \%$ \\
\hline
\end{tabular}


Berdasarkan nilai-nilai tersebut, dapat dibentuk histogram data kelompok sebagai berikut:

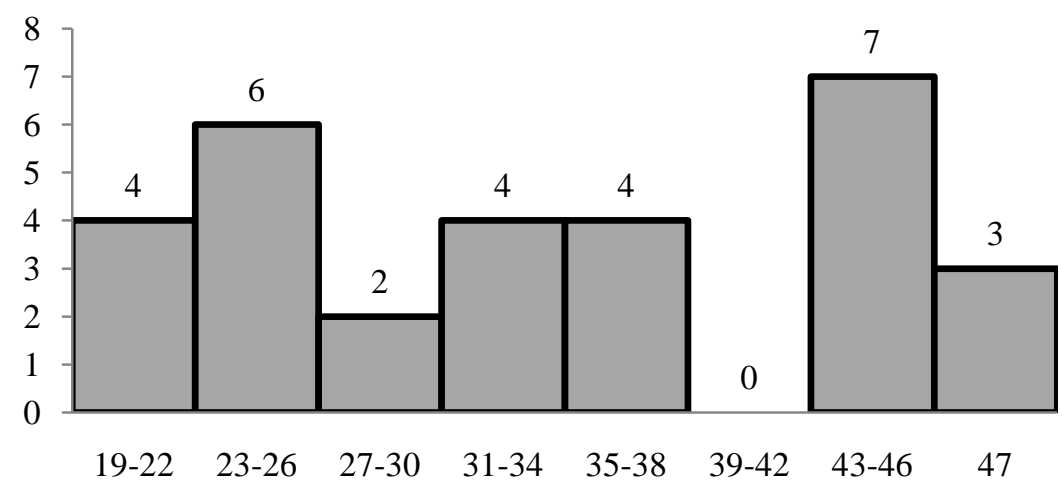

Gambar 1. Histogram Data Post-test Kelas Eksperimen

Sedangkan hasil perhitungan rata-rata, varians, standar deviasi kelas eksperimen dan kontrol dapat dilihat pada tabel di bawah ini:

Tabel 7. Hasil Perhitungan Rata-rata, Varians, Standar Deviasi kelas Eksperimen dan Kontrol

\begin{tabular}{|c|c|c|c|c|c|c|}
\hline Kelompok & $\mathbf{N}$ & $\begin{array}{c}\text { Rata- } \\
\text { rata }\end{array}$ & Varians & $\begin{array}{c}\text { Standar } \\
\text { Deviasi }\end{array}$ & Maksimal & Minimal \\
\hline Eksperimen & 30 & 31,970 & 25,531 & 5,053 & 46 & 19 \\
\hline Kontrol & 30 & 28,576 & 18,940 & 4,532 & 40 & 15 \\
\hline
\end{tabular}

\section{Pembahasan Penelitian}

Berdasarkan pada kondisi awal ditunjukkan bahwa kemampuan awal siswa antara kelas eksperimen dan kelas kontrol relatif sama. Pada kelas eksperimen nilai rata-rata kemampuan awal siswa adalah 21,667 sedangkan rata-rata kemampuan awal siswa kelas kontrol adalah 21,600. Dari hasil pengujian hipotesis diperoleh $t_{\text {hitung }}=2,925>\mathrm{t}_{\text {tabel }}=2,0018$ yang berarti terdapat pengaruh strategi berhitung (different strategies) terhadap hasil belajar matematika siswa pada materi operasi bilangan bulat di kelas III SD Negeri No 114349 Sidua-dua Tahun Ajaran 2016/2017.

Terlihat bahwa siswa pada kelas eksperimen yang diajarkan dengan strategi berhitung (different strategies) lebih baik. Hal ini terjadi karena adanya persaingan sehat antara siswa dan siswa dapat melakukan perhitungan lebih mudah memahami dengan strategi berhitung (different strategies). Sedangkan pada kelas kontrol yang diajarkan dengan algoritma tradisional tidak semua siswa mampu menguasai materi pelajaran dengan baik dan sempurna. Hal ini dikarenakan keterbatasan waktu siswa dalam mengerjakan tugas-tugas yang diberikan guru. Selain itu siswa hanya mampu melakukan perhitungan dengan cara berurutan dengan cara penghapalan penjumlahan.

Temuan yang ditemui di lapangan, bahwa siswa yang berada pada kelas eksperimen atau yang menggunakan strategi berhitung (different strategies) mampu menyelesaikan soal berbentuk penjumlahan dan pengurangan, serta 
Nurdalilah: Pengaruh Strategi Berhitung (Different Strategies) terhadap Hasil Belajar Matematika Siswa pada Operasi Bilangan Bulat di Kelas III SD Negeri No 114349 Sidua-Dua

operasi perhitungan yang terdapat dalam soal cerita. Hal ini terlihat dari lembar tes hasil jawaban siswa yang menggunakan strategi berhitung (different strategies) dalam menyelesaikan soal tes akhir belajar.

Strategi berhitung yang umumnya digunakan siswa kelas ekperimen adalah memecah angka sesuai nilai tempatnya untuk soal-soal penjumlahan. Pengelompokan dua nilai tempat sekaligus untuk pengurangan bilangan tiga angka, strategi ini diluar prediksi strategi berhitung yang akan ditemukan siswa. Mereka menggunakan media yang telah dibahas pada bab sebelumnya. Dari ketiga media yang diperkenalkan dalam penelitian ini, seluruh siswa kelompok strategi berhitung (different strategies) lebih mudah menggunakan bagan ratusan angka. Sebagai contoh pada soal $173+48$, siswa pada kelompok ini memecahnya menjadi 100, 70, dan 3 dengan 40 dan 8 . Bagian-bagian tersebut digabungkan sesuai nilai tempatnya diperoleh 100, 110 yang kemudian dipecah lagi menjadi 100 dan 10 serta 11 yang kemudian dipecah lagi menjadi 10 dan 1 sehingga diperoleh 100, 100,10, 10, dan 1 diperoleh 221. Berikut ini contoh strategi berbeda dalam lembar kerja. Cara lain siswa menambahkan bilangan pertama dengan cara memcah terlebih dahulu bilangan kedua dengan berurutan dari nilai tempat yang paling besar $173+40$ kemudian $213+8=221$.

Pengelolaan kelas dengan menggunakan strategi pembelajaran diharapkan mampu mencapai tujuan pembelajaran yang diinginkan dengan demikian, guru memiliki peranan penting untuk menerapkan strategi pembelajaran yang tepat digunakan dalam proses pembelajaran. Disamping itu, guru sebagai motivator dan fasilitator dituntut untuk lebih mengaktifkan kegiatan siswa dalam pembelajaran.

Berdasarkan hasil pengujian hipotesis pada uji t telah membuktikan dan memberikan temuan bahwa, terdapat pengaruh strategi berhitung (Different Strategies) terhadap hasil belajar matematika siswa pada operasi bilangan bulat di SD Negeri No 114349 Sidua-dua Tahun Ajaran 2016/2017.

\section{E. Kesimpulan dan Saran}

\section{Kesimpulan}

Berdasarkan hasil analisis, temuan dan pembahasan yang telah dikemukakan pada bab sebelumnya diperoleh beberapa simpulan yang berkaitan dengan hasil belajar dan strategi pembelajaran. Simpulan tersebut sebagai berikut:

a. Terdapat pengaruh strategi berhitung (different strategies) terhadap hasil belajar matematika siswa pada materi operasi bilangan bulat di kelas III SD Negeri No 114349 Sidua-dua Tahun Ajaran 2016/2017.

b. Tidak terdapat pembelajaran strategi algoritma tradisional terhadap hasil belajar matematika siswa pada materi operasi bilangan bulat di kelas III SD Negeri No 114349 Sidua-dua Tahun Ajaran 2016/2017.

c. Terdapat perbedaan yang signifikan antara pengaruh strategi berhitung (different strategies) dan pembelajaran algoritma tradisional terhadap hasil belajar matematika siswa di kelas III SD Negeri No 114349 Sidua-dua Tahun Ajaran 2016/2017. 


\section{Saran}

Berdasarkan hasil penelitian ini, peneliti ingin memberikan saran-saran sebagai berikut:

a. Untuk guru mata pelajaran Matematika, agar memilih stratgi pembelajaran yang paling sesuai dengan materi pokok yang diajarkan, seperti strategi berhitung (different strategies), agar nantinya dapat menunjang proses pembelajaran yang lebih aktif, efektif dan efisien.

b. Untuk peneliti selanjutnya yang ingin melakukan penelitian yang sama, disarankan untuk mengembangkan penelitian ini dengan mempersiapkan sajian materi lain, menggunakan strategi yang berbeda dan dapat mengoptimalkan waktu guna meningkatkan hasil belajar matematika siswa

\section{DAFTAR PUSTAKA}

Al-Tabany, Trianto Ibnu Badar. 2014. Mendesain Model Pembelajaran Inovatif, Progresif dan Kontekstual. Jakarta : Prenadamedia Grup.

Huda, Miftahul. 2014. Model-Model Pembelajaran, Isu-isu Metodis dan Pragmadimatis. Yogyakarta: Pustaka Belajar.

Shoimin, Aris. 2014. Model Pembelajaran Inovatif dalam Kurikulum 2013. Yogyakarta: Ar Ruz Media.

Suyono dan Harianto. 2014. Belajar dan Pembelajaran. Bandung: Remaja Rosdakarya. 